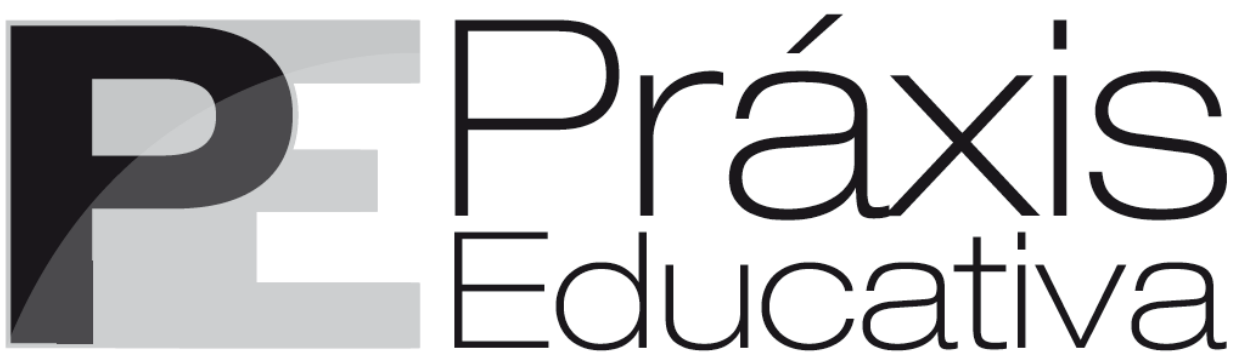

ISSN 1809-4309 (Versão online) DOI: 10.5212/PraxEduc.v.11i2.0014

\title{
TELLO, César G. (Comp.). Los objetos de estudio de la política educativa: hacia una caracterización del campo teórico. Buenos Aires: Autores de Argentina, 2015. 248 p. $^{*}$
}

Fernando Cesar Sossai*

\section{Escritos sobre políticas educacionais e seus possíveis objetos de estudo}

248 páginas, três partes, 11 capítulos, 13 autores/as procedentes de quatro países distintos (Argentina, Brasil, México e Uruguai). Eis alguns dados que sinalizam o esforço colaborativo que deu origem ao livro "Los objetos de estudio de la política educativa: hacia una caracterización del campo teórico", organizado pelo professor César G. Tello (2015) ${ }^{1}$. Aos que se interessam pelo debate sobre/em políticas educacionais (PE), sem dúvida, a leitura da obra é de vital importância.

No conjunto, o livro (capa apresentada na Figura 1) pode ser considerado uma produção epistemológica coletiva na qual cada autor promove interessantes debates sobre aspectos teóricos e metodológicos que atravessam o "campo teórico da política educacional" e conformam seus "objetos de estudo"' (TELLO, 2015, p. 16).

\footnotetext{
* Disponível em: <http://www.relepe.org/index.php/libros>. Acesso em: 20 dez. 2015.

** Professor da Univille e Doutorando em Educação (PPGE/UDESC). E-mail: < fernandosossai@gmail.com>.

1 Professor das universidades nacionais de La Plata, Tres de Febrero e San Martín (Argentina). Diretor de Investigação e Desenvolvimento da Universidad Nacional de Tres de Febrero. Diretor da Red de Estudios Teóricos y Epistemológicos en Política Educativa - ReLePe (<http://www.relepe.org $>$ ). Diretor Editorial da Revista de Estudios Teóricos y Epistemológicos en Política Educativa - RETEPE (<http://www.relepeenrevista.org $>$ ).

${ }^{2}$ De partida, informo que todas as citações doravante apresentadas são livres traduções que realizei (EspanholPortuguês). Junto a cada uma delas, registro exatamente o número da página de onde foram extraídas em Tello (2015). Vale também salientar que busquei sempre respeitar o sentido contextual dos parágrafos dos quais foram retiradas de maneira a evitar distorções em relação às palavras/reflexões de seus autores originais.
}

Práxis Educativa, Ponta Grossa, v. 11, n. 2, p. 535-541, maio/ago. 2016 Disponível em: <http://www.revistas2.uepg.br/index.php/praxiseducativa $>$ 
Figura 1 - Capa de "Los objetos de estudio de la política educativa: hacia una caracterización del campo teórico"

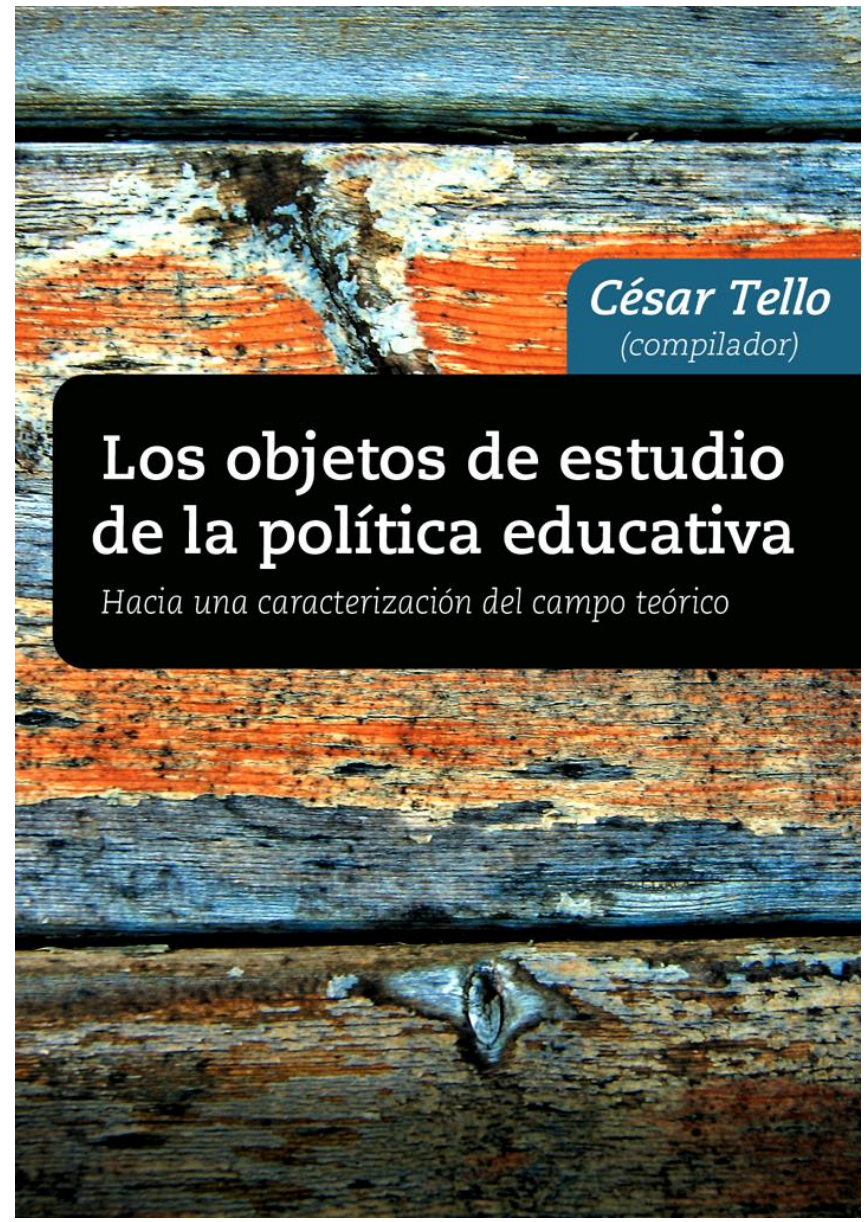

Fonte: Acervo do autor, 2015.

Pela seriedade e rigorosidade analítica de cada capítulo, a obra é uma contribuição significativa para todos os estudiosos que desejam encampar reflexões sobre o papel exercido pelos diferentes enfoques, perspectivas, posicionamentos e abordagens epistemológicas que assumimos quando o assunto é a produção do conhecimento em PE.

Da perspectiva de seu organizador, a publicação é também uma tentativa de caracterizar o "campo da política educacional" tomando como referência os "eixos" de sua "estrutura teórica". Trata-se de um aglomerado de escritas que ressaltam marcadores teórico-metodológicos que, pela sua potência reflexiva, deveriam ser levados em conta por quem se lança ao "estudo teórico e epistemológico em política educacional” (p. 14).

Além disso, o livro é bastante ousado ao enfrentar um desafio intelectual que atormenta todas as investigações em PE, qual seja, as questões relacionadas à escolha de um "método" para o estudo de política(s) educacional(is). Dito de maneira mais clara, os autores não se esquivam da análise de um ponto que exige efetiva atenção dos investigadores que atuam no campo teórico da PE: "O modo como se constrói metodologicamente a investigação a partir de uma determinada perspectiva e posicionamento epistemológico" (p. 13).

Como não poderia deixar de ser, tal questão é trabalhada de maneira diferente pelos autores de cada capítulo. $\mathrm{Na}$ obra, são recorrentes digressões sobre a não neutralidade e os valores ideológicos da ciência, a necessidade de se problematizar expectativas sociais, 
TELLO, César G. (Comp.). Los objetos de estudio de la política educativa...

econômicas, políticas e educacionais que cruzam o campo e interferem no processo de elaboração de estudos em PE, o uso meramente técnico do conhecimento em PE, a falta de explicitação clara dos aspectos teóricos e metodológicos que embasam uma determinada investigação em PE, entre outras que parecem expressar a dedicação dos escritores às reflexões de caráter "epistemetodológico", de "método" (p. 13 e 16).

Conforme mencionado, o livro está dividido em três partes. A primeira, intitulada "Consideraciones teóricas acerca del objeto de estudio de la política educativa", conta com quatro capítulos sensíveis à discussão sobre os "sentidos teóricos" atribuídos aos "objetos de estudo de política educacional". Nessa parte, ganha relevo um conjunto de discussões sobre conceitos, noções e categorias provenientes de diferentes matizes de conhecimento e que poderiam ser mobilizadas para subsidiar/orientar estudos em PE (Ciências Sociais, Ciência Política, Humanidades, Educação, etc.).

A segunda parte denomina-se "Enfoques epistemetodológicos en el abordaje de los objetos de estudio de la política educativa" e também é integrada por quatro capítulos. Nela, os autores analisam as relações de associação entre um "modelo" (ou uma "perspectiva teórica") e uma "metodologia analítica" quando definem/constroem seus "objetos de estudo" em PE (p. 16).

Já os três últimos capítulos compõem a terceira parte do livro, a qual recebeu a alcunha de "Los objetos de estudio desde relevamientos empíricos. Los casos de Argentina, Brasil y México". Um dos pontos interessantes dessa parte é que, à sua maneira e com maior ou menor grau de profundidade, cada pensador busca apresentar uma "produção de conhecimento" em PE a partir de "estudos empíricos" sobre publicações científicas que circulam nos países onde atuam (p. 16).

Feita uma caracterização geral da obra, de agora em diante, vejamos a proposta, como se estruturam e como procedem cada um dos autores de seus respectivos capítulos.

Escrito por Jefferson Mainardes, o primeiro capítulo denomina-se "Reflexiones sobre el objeto de estudio de la política educativa". Nele, o autor se propõe "apresentar algumas reflexões sobre o objeto de estudo de política educacional" dialogando com as "análises de investigadores e publicações do Brasil", assim como com as "contribuições de autores de referência do campo" (destacadamente Andrew Sayer, Roger Dale e Stephen Ball). Acreditando que "os estudos e as publicações de natureza teórica são essenciais para o fortalecimento da política educacional enquanto campo específico", Mainardes estrutura seu capítulo em cinco partes cujos conteúdos são alimentados por uma densa pesquisa, análise, síntese e interpretação de bibliografias de fundamental importância para os investigadores de PE (p. 25). Tal procedimento leva o autor à seguinte conclusão: "o objeto de estudo do campo é a análise de política educacional formulada pelo aparelho do Estado, em seus diversos níveis e esferas (federal, estadual e municipal) ${ }^{3}$. Essa análise abarca estudos de natureza teórica, estudos com base empírica e estudos para a superação da realidade" (p. 27). Enfim, o texto é capital para quem intenciona avançar seus estudos para além de "análises descritivas", aprofundando análises sobre o material empírico com a qual interage, assim como para quem deseja atingir níveis de abstração mais elevados, abarcando em

\footnotetext{
${ }^{3}$ É importante mencionar aqui que Mainardes (2015, p. 27) reconhece “[...] que os estudos de política educacional incluem também questões relacionadas às demandas educacionais e sua atenção (ou não), discussões sobre o direito à educação, os movimentos de luta pela garantia do direito à educação, a legislação educacional, entre outros aspectos". Todavia, especificamente em seu artigo, o autor focaliza a forma como os investigadores realizam suas análises em política educacional.
}

Práxis Educativa, Ponta Grossa, v. 11, n. 2, p. 535-541, maio/ago. 2016 Disponível em: <http://www.revistas2.uepg.br/index.php/praxiseducativa > 
suas reflexões não "apenas eventos" em PE, mas também "os mecanismos e as estruturas" que os configuram no mundo (p. 39).

O segundo capítulo, intitulado "Los objetos de estudio de la política educativa: tres argumentaciones epistemológicas para su análisis", tem como pretensão "apresentar algumas reflexões conceituais" que estão sendo desenvolvidas no âmbito do "Enfoque das Epistemologias da Política Educacional (EEPE)" que, por sua vez, "tem por finalidade propor um esquema de análise sobre o campo de investigação e produção de conhecimento em política educacional" (p. 43). Ao longo do texto, seu autor, César Tello, empreende uma rica reflexão bibliográfica, revisando escritos que nos inspiram a pensar como poderia ser construído um campo de política educacional pautado em premissas teórico-metodológicas que valorizassem a "complexidade", a "multidisciplinaridade" e a "multidimensionalidade de posicionamento e perspectivas epistemológicas" ao se desenvolver uma investigação em PE (p. 59). A meu ver, o saldo das seis partes que formam o capítulo é a reafirmação e o amadurecimento de conceitos e categoriais sobre o EEPE apresentadas/os em publicações anteriores (por exemplo em TELLO; MAINARDES, 2015; TELLO, 2013).

"Fundamentos epistemológicos de las políticas educativas: de la razón moderna al discurso de inclusión social" foi o título dado ao terceiro capítulo do livro. De autoria de Lindomar Wessler Boneti o texto encontra-se organizado em cinco partes e busca "analisar os fundamentos epistemológicos das políticas públicas educacionais, adotando a perspectiva metodológica de associar políticas públicas à teoria do Estado". Tal arranjo visa superar enfoques que vinculam essas políticas a meras "ações de governo, centralizando nas análises, avaliações dos resultados e do gerenciamento dos recursos públicos" (TELLO, 2015, p. 63). O autor assim explicita seus recortes e opções de análise:

[...] se analisam as implicações teóricas, metodológicas e políticas do processo de elaboração e implementação das políticas públicas educacionais em uma dimensão temporal e histórica. Argumentando que apresentam duas fases: 1. as políticas públicas educacionais tendo como fundamento epistemológico a Razão Moderna (quando a técnica era uma referência da verdade e do saber, apresentando como agentes definidores, basicamente, o meio produtivo e o Estado); 2. a partir de uma perspectiva contemporânea, quando se rejeita o absolutismo da verdade técnica como parâmetro, situando do lado do Estado e do meio produtivo novos agentes definidores de políticas públicas. Por isso é necessário trazer ao debate a questão das novas lutas sociais, que buscam resgatar ao sujeito, as identidades e as desigualdades sociais. (TELLO, 2015, p. 63).

Em que pese a amplitude, o texto é enriquecedor, sobretudo, pelas análises das contradições históricas em relação "a maneira de pensar a escola", bem como pela defesa de que as "políticas públicas educacionais" resultam da "dinâmica do jogo de forças, que se estabelecem no âmbito das relações de poder constituídas pelos grupos econômicos, políticos, classes sociais e demais organizações da sociedade civil". É em sintonia com esse pressuposto que se constroem "um conjunto de decisões atribuídas à instituição estatal, que provocam o direcionamento (e/ou redirecionamento) dos rumos de ações de intervenção administrativa do Estado na realidade social $[\ldots] "$ " (p. 63 e 76).

Encerrando a primeira parte, "Una contribución desde la ciencia política al estudio de las políticas educativas: el rol de las instituciones, las ideas y los actores", de Nicolás Bentancur, foi elaborado tomando como referência as seguintes indagações: "como se pode explicar [...] a orientação e direcionalidade da tomada de decisão nas políticas educacionais?"; ao que atende a escolha ou o desprezo de "certas alternativas" em políticas educacionais?; "por quais razões [...] países que compartilham um conjunto de características sociais e políticas, e enfrentam

Práxis Educativa, Ponta Grossa, v. 11, n. 2, p. 535-541, maio/ago. 2016 Disponível em: <http://www.revistas2.uepg.br/index.php/praxiseducativa > 
TELLO, César G. (Comp.). Los objetos de estudio de la política educativa...

problemas similares em seus sistemas educacionais, costumam diferir nas políticas educacionais que formulam?" (p. 79). A partir dessas perguntas, Bentancur apresenta um conjunto de "variáveis explicativas" sobre o "direcionamento das políticas" públicas, dando destaque ao debate específico sobre PE. Ao final de sua escrita, oferece ainda um "Anexo" contendo um quadro no qual "esquematiza" uma "proposta para a comparação de políticas" (p. 80). Vale uma leitura atenta de cada um dos oito itens que dão forma ao capítulo.

Abrindo a segunda parte da obra, o texto de Renata Giovine, "La analítica de gobierno. Aportes al estudio de las políticas educativas", busca como referência os "aportes do pensamento de Foucault" para desenvolver três interrogações, a saber, "como se poderia caracterizar o campo teórico de política educacional?", "qual seria seu objeto de estudo?", "a partir de quais perspectivas epistemológicas pode ser abordado?” (p. 105). Ao longo de três seções, a autora revisa e interpreta variadas publicações de Michel Foucault com o objetivo de fazer uma defesa: os investigadores de políticas educacionais deveriam estar atentos à noção de "analítica de governo", uma vez que ela "permitiria renunciar a pretensão de unicidade e essencialismo das tradicionais concepções de política educativa" e entendê-las como "formas específicas de práticas de governo" (p. 121). Desta perspectiva, ganharia outra relevância a "análise de leis, resoluções, posicionamentos políticos, programas, projetos, planos e outros documentos autorizados, assim como aqueles desqualificados", já que a análise dos "mecanismos discursivos" colocados em jogo quando se constituem as "políticas oficiais" ficariam mais evidentes e desnaturalizados (p. 120).

Já o capítulo seis, "Lo político y las políticas en materia educativa: el rescate de la fraternidad", elaborado por Enrique Del Percio e María Mercedes Palumbo, se interessa por discutir a "fraternidade" como um "eixo" de "índole política" (como um "princípio" de "origem" e de "fundamento") para se "abordar" a "política educacional" como um "campo teórico e prático" (p. 131 e 136). Advogando em favor de uma "abordagem pós-fundacional das políticas educacionais", os autores finalizam o texto sublinhando que uma concepção de PE que assume a "categoria (e as práticas) da fraternidade coloca no centro da cena a diferença" (p. 138 e 140).

'Política', políticas públicas y política educativa: alcances y enfoques alternativos, escrito por Oscar Espinoza, constitui-se como o sétimo capítulo da referida obra. De acordo com Espinoza, o propósito do seu texto é apresentar uma "perspectiva crítica em relação a três aspectos que frequentemente são objeto de análises divergentes dependendo do contexto ou do marco conceitual" que se adota para abordá-los, quais sejam: a) "os conceitos de 'política', políticas públicas e política educacional e suas implicâncias e inter-relações" quando do "momento" no qual se realiza a "análise de políticas"; b) "alguns procedimentos para conduzir a análise de políticas"; c) "algumas tendências, observáveis na implementação de políticas educacionais, em relação aos fundamentos conceituais da teoria crítica e da teoria funcionalistapositivista" (p. 143). Metodologicamente, Espinoza define o seu fazer como de "natureza qualitativa de caráter descritivo-analítico e que emprega fontes secundárias de tipo documental" (p. 144). Após a leitura de quatro interessantíssimas partes, é possível afirmar que o escrito é uma excelente contribuição para todos os investigadores de PE que se interessam por construir uma rigorosidade científica no uso dos termos política, políticas públicas e política educacional e, para além disso, para todos que desejam desenvolver algumas definições correntes sobre tais termos que, por vezes, mais confundem do clarificam, mais turvam do que sinalizam possibilidades operatórias quando do trabalho epistemológico com tais conceituações.

Altair Alberto Fávero e Leandro Carlos Ody são os autores do capítulo "Falibilismo como perspectiva epistemológica en las investigaciones en políticas educativas. Caracterizando el campo teórico", o oitavo do livro. A principal preocupação desses estudiosos é a de sugerir algumas "reflexões sobre o falibilismo como perspectiva epistemológica [...] que permitiriam

Práxis Educativa, Ponta Grossa, v. 11, n. 2, p. 535-541, maio/ago. 2016 Disponível em: <http://www.revistas2.uepg.br/index.php/praxiseducativa $>$ 
analisar as investigações em políticas educacionais no cenário das realidades atuais" (p. 161). Segundo pensam, tal opção é a melhor estratégica para se "enfrentar os desafios e impasses produzidos pelo cenário de crise educacional, que demonstraram as inumeráveis pesquisas em nosso tempo" (p. 162). Apresentando análises muito próprias sobre textos que recorrentemente circulam entre os investigadores de PE brasileiros, assim como leituras também muito próprias sobre as matizes epistemológicas que conformam o pensamento de autores há muito tempo conhecidos no campo da Educação (nomeadamente Peirce e Dewey), Fávero e Ody enfatizam que a adoção da "perspectiva falibilista na identificação e análise de pesquisas educacionais" oportuniza uma "atitude de abertura às múltiplas possibilidades de reconhecimento das diferenças" e, sobretudo, de eleger o "diálogo como princípio investigativo" (p. 178).

Dando corpo à terceira parte, os três últimos capítulos podem ser aqui tratados de maneira conjunta, dada as suas aproximações temáticas, teórico-metodológicas, empíricas e analíticas. São eles os seguintes:

"La investigación en política educativa en Argentina: un análisis de la producción en revistas especializadas”, de autoria de Jorge M. Gorostiaga e César G. Tello;

"La investigación en políticas educativas en Brasil: ¿de qué estamos hablando?", escrito por Ângelo Ricardo de Souza;

"El campo teórico de la política educativa y su objeto de estudio. Un campo específico e interrelacionado con el campo de la educación”, elaborado por Jaime Moreles Vázquez.

Para além de apresentarem dados relevantes sobre a constituição dos campos de PE nos Estados Nacionais onde atuam (Argentina, Brasil e México), sobre os temas repetidamente incluídos na agenda de trabalho de investigadores acadêmicos dedicados à pesquisa de política(s) educacional(is), de sublinhar informações sobre como órgãos de governo, universidades, ONGs e organismos multilaterais supranacionais, por vezes, estão mais ou menos articulados na promoção de determinadas políticas educacionais (em detrimentos de outras), de dar visibilidade a periódicos qualificados que desde longa data vem publicando artigos e outros documentos sobre PE, entre outros aspectos... do meu ponto de vista, no conjunto, os três textos podem ser significados como registros sobre os limites, as possibilidades e os desafios que se desdobram da operação intelectual dos constructos teórico-metodológicos tratados em cada capítulo que antecede a parte final da obra. Em outras palavras, tão interessante quanto o conteúdo formalmente explicitado como resultado da pesquisa que deu origem ao capítulo, o que se evidencia em cada linha da terceira parte é como cada autor, a partir de seus respectivos lugares acadêmicos, institucionais e intelectuais, analisa, compreende, interpreta e aciona os conceitos, as noções, as categorias e as metodologias que foram problematizadas por eles mesmos ou por seus pares ao longo do livro (ou no campo teórico da PE em geral). Uma postura arguta pode ser a melhor maneira de fazer a leitura de tais capítulos.

Por fim, vale a pena mencionar que um livro possui muitos leitores imaginados (destinatários, receptores, usuários pretendidos). Portanto, os textos compõem a obra compilada por Tello (2015) são importantes de serem conhecidos por pesquisadores acadêmicos, por educadores que atuam em diferentes cargos, níveis e modalidades da educação, por gestores que prestam serviços em variadas esferas da coisa pública e/ou por qualquer pessoa interessada em saber um pouco mais sobre os possíveis lugares epistemetodológicos que a ciência poderia ocupar em estudos de política(s) educacional(is) comprometidos com os fenômenos educacionais que verte em objetos de análise.

Práxis Educativa, Ponta Grossa, v. 11, n. 2, p. 535-541, maio/ago. 2016 Disponível em: <http://www.revistas2.uepg.br/index.php/praxiseducativa > 


\section{Referências}

TELLO, C. G. Notas reflexivas y descriptivas sobre el enfoque de las epistemologías de la política educativa. Conjectura: Filosofia e Educação, Caxias do Sul, v. 18, n. especial, p. 48-62, 2013.

TELLO, C. G. (Comp.). Los objetos de estudio de la política educativa: hacia una caracterización del campo teórico. Buenos Aires: Autores de Argentina, 2015. Disponível em: <http://www.relepe.org/index.php/libros>. Acesso em: 20 dez. 2015.

TELLO, C. G.; MAINARDES, J. Revisitando el enfoque de las epistemologías de la política educativa. Práxis Educativa, v. 10, n. 1, p. 153-178, jan./jun. 2015. 